\title{
Medical Therapy for Fibroids: What Next for Ulipristal Acetate?
}

\author{
Emmanuel Ekanem (D) · Vikram Talaulikar
}

Received: September 10, 2020 / Accepted: October 28, 2020 / Published online: November 17, 2020

(c) The Author(s) 2020

\begin{abstract}
Ulipristal acetate (UPA) was introduced as a novel progesterone receptor modulator as effective therapy for symptomatic fibroids. Randomised clinical trials established its effectiveness in the management of heavy menstrual bleeding due to uterine leiomyomas. The trials did not find any significant evidence of clinical harm to the participants. Recently, however, there have been reports of liver injury necessitating liver transplant in women who have had UPA treatment. This has led to the suspension of UPA as one of the medical therapies in the
\end{abstract}

E. Ekanem $(\bowtie)$

Speciality Trainee in Obstetrics and Gynaecology,

University Hospitals of Leicester NHS Trust,

Leicester LE1 5WW, UK

e-mail: Emmanuel.Ekanem@nhs.net

V. Talaulikar

Reproductive Medicine Unit, University College

London Hospital, 235 Euston Road,

London NW1 2BU, UK treatment for uterine fibroids while the European Medicines Agency (EMA) conducts a review of liver injury risk with its use. The European Medicine Agency safety committee has advised that women should stop taking $5 \mathrm{mg}$ UPA and that no new patients should commence treatment with the medicine until the ongoing review is completed. In this article, we review the rise of UPA as one of the emerging medical therapies for symptomatic uterine fibroids and the subsequent reports of adverse events leading to the suspension of its use.

Keywords: Fibroids; Medical; Ulipristal acetate; Women's health 


\section{Key Summary Points}

Ulipristal acetate (UPA) is selective progesterone receptor modulator effective for the treatment of symptomatic uterine fibroids

Randomised clinical trials established its effectiveness in the management of heavy menstrual bleeding due to uterine leiomyomas. The trials did not find any significant evidence of clinical harm to the participants

Recently, however, there have been reports of liver injury necessitating liver transplant in women who have had UPA treatment

This has led to the suspension of UPA as one of the medical therapies in the treatment for uterine fibroids while the European Medicines Agency (EMA) conducts a review of liver injury risk with its use

In this article, we review the rise of UPA as one of the emerging medical therapies for symptomatic uterine fibroids and the subsequent reports of adverse events leading to the suspension of its use

\section{DIGITAL FEATURES}

This article is published with digital features, including a summary slide, to facilitate understanding of the article. To view digital features for this article go to https://doi.org/10.6084/ m9.figshare.13143791.

\section{INTRODUCTION AND OVERVIEW OF MEDICAL TREATMENTS FOR UTERINE FIBROIDS}

Ulipristal acetate (UPA) is one of the selective progesterone receptor modulators (SPRMs) that was found useful in treating women with symptomatic uterine fibroids in addition to its use as an effective emergency contraceptive. Initially developed in 2012 as 'Ella one' for emergency contraception, its use has been extended to the treatment of symptomatic uterine leiomyoma especially in women who suffer from menorrhagia $[1,2]$.

Uterine fibroids (leiomyomas) are benign monoclonal tumours of the uterine myometrium that affect $20-40 \%$ of reproductive-aged women [3-5]. Uterine fibroids may present through a variety of symptoms such as menorrhagia, pressure symptoms (on bowel/bladder), pelvic mass, pelvic pain and subfertility. They have also been associated with increased risk of pregnancy morbidities such as miscarriage, red degeneration, antepartum or postpartum haemorrhage, preterm labour and difficult/obstructed labour. Rare complications of fibroids include malignant transformation, polycythaemia and renal cell carcinoma $[3,6]$.

Traditional management options for symptomatic fibroids include conservative, medical and surgical therapies. Medical treatments include antifibrinolytics, combined oral contraceptives, selective oestrogen receptor modulators, aromatase inhibitors, levonorgestrel intrauterine system (LNG-IUS) and gonadotrophin-releasing hormone (GnRH) analogues. GnRH analogues have been mostly used widely in the short term, and while they do cause shrinkage of fibroids, they can only be used temporarily as a measure in the perimenopausal phase or preoperatively to shrink the size of the fibroid and influence the type and route of surgery, restore haemoglobin levels and apparently reduce blood loss at surgery. Downsides of treatment with GnRH analogues are rebound in the growth of the fibroids when its used is stopped and the loss of bone mineral density.

There are suggestions that LNG-IUS (Mirena) can cause a substantive reduction in menstrual blood loss in women with fibroids, but as yet there is not enough evidence to back its use in women with moderate to large/multiple fibroids where there is an increased rate of its expulsion.

Interventional therapies for fibroids include magnetic resonance focused ultrasound, 
radiofrequency ablation, percutaneous microwave ablation and embolisation of the uterine artery. Other novel therapies that are being explored include somatostatin analogues, vitamin $\mathrm{D}$ and epigallocatechin gallate $[3,7,8]$. Surgical treatments for fibroids include myomectomy, which can be through hysteroscopic, laparoscopic/robotically assisted laparoscopic, abdominal or vaginal routes depending on the suitability $[3,9,10]$. Hysterectomy remains the permanent cure for women who have finished childbearing and no further reproductive wishes and for women not wishing to conserve their uterus [10].

The use of UPA and GnRH analogues has been explored before surgery as these agents are known to diminish the size of uterine fibroids preoperatively $[3,7,11,12]$. Surgical treatment carries with it the risk of infection, bleeding, adhesions, injuries to viscera, postoperative morbidities and mortality as well. Although the radiological options of treatments are relatively new, they may not be suited for all women and often require facilities and equipment that are not readily obtainable especially in resourcepoor settings.

UPA therapy for symptomatic uterine fibroids appeared to be a valid medical option that promised a reduction in fibroid related bleeding.

\section{ULIPRISTAL ACETATE- MECHANISM OF ACTION}

UPA is one of the members of a family of drugs known as selective progesterone receptor modulators (SPRMs). Other members in this family are mifepristone (RU-486), asoprisnil (J-867) and telapristone acetate (CBD-4124) [10, 13]. Although licensed for the management of heavy uterine bleeding due to fibroids and preoperative treatment of fibroids to achieve a reduction in their size before surgery, concerns were subsequently raised about its association with possible liver injury and the use restricted over the last 2 years [3, 14]. SPRMs work by reducing serum levels of luteinising hormone (LH) and follicle-stimulating hormone (FSH) in addition to sustaining oestrogen levels in the mid-follicular phase of the menstrual cycle [15]. Ulipristal acetate acts on higher centres in the brain besides local actions on the fibroid tissue $[1,15-17]$. SPRMs alter the expression of growth factors such as insulin-like growth factor-1 (IGF1 ), tumour necrosis factor (TNF)-alpha and epidermal growth factor (EGF) and Bcl-2 $[1,3,10,18,19]$. They also modulate the expression of metalloproteinases matrix connective tissue and tissue inhibitor of collagen and metalloproteinases in myoma cells diminishing tissue integrity. By modulating the ratio of progesterone receptor isoforms, they reduce the cell viability and expression of growth factors, thus bringing about apoptosis [1, 15]. SPRMs do not seem to have as much effect on the smooth muscle fibres of the normal myometrium in cell cultures compared to the effect they have on uterine fibroid cells, thus raising the likelihood of exploring this differential effect in the treatment of fibroids while sparing normal uterine smooth muscles [15].

\section{ULIPRISTAL ACETATE-SUMMARY OF CURRENT CLINICAL EVIDENCE}

Several large studies and clinical trials assessed the use of UPA in the control of symptoms of uterine leiomyomata and in the diminution of fibroid volume (Table 1). Compared with GnRH analogues, UPA causes fewer hypoestrogenic symptoms.[15]

\section{PEARL I}

One of the first trials that assessed the effect of UPA on uterine fibroids is the PEARL I trial [20]. Women with symptomatic fibroids were assigned randomly to receive treatment with tablets of UPA for 13 weeks. This trial looked at the treatment with UPA at a dose of $5 \mathrm{mg}$ per day in 96 women or $10 \mathrm{mg}$ per day in 98 women with a placebo arm involving 48 women in patients with symptoms such as menorrhagia and anaemia [18].

At 13 weeks, the control menstrual blood loss was achieved in $91 \%$ of the women who received $5 \mathrm{mg}$ of UPA, $92 \%$ of those receiving 
Table 1 Summary of the PEARL trials with UPA

\begin{tabular}{|c|c|c|c|}
\hline Study & Duration & Efficacy & Safety profile (adverse effects) \\
\hline $\begin{array}{l}\text { PEARL } \\
\text { I }\end{array}$ & 13 Weeks & $\begin{array}{l}\text { Bleeding was controlled in } 91 \% \text { of women taking } \\
5 \mathrm{mg} \text { and } 92 \% \text { of women taking } 10 \mathrm{mg} \text { and } \\
19 \% \text { in placebo } \\
\text { Reduction in fibroid volume was } 21 \%, 12 \% \text { and } \\
3 \% \text { for women taking } 5 \mathrm{mg}, 10 \mathrm{mg} \text { and placebo } \\
\text { respectively } \\
\text { Amenorrhea rate: } 73 \%, 82 \% \text { and } 6 \% \text { in women } \\
\text { taking } 5 \mathrm{mg}, 10 \mathrm{mg} \text { and placebo respectively }\end{array}$ & $\begin{array}{l}\text { Benign changes on the endometrium were } \\
\text { noted on histology but } 6 \text { months these } \\
\text { were no longer present } \\
\text { Uterine haemorrhage } \\
\text { Myoma projecting through the cervix } \\
\text { Others: headaches and breast tenderness }\end{array}$ \\
\hline $\begin{array}{l}\text { PEARL } \\
\text { II }\end{array}$ & 13 Weeks & $\begin{array}{l}\text { Control of bleeding occurred in } 90 \% \text { of women } \\
\text { taking } 5 \mathrm{mg} \text { and } 98 \% \text { of women taking } 10 \mathrm{mg} \\
\text { and } 89 \% \text { in leuprolide arm } \\
\text { Amenorrhea rate: } 5 \text { days, } 7 \text { days and } 21 \text { days in } \\
\text { women taking } 5 \mathrm{mg}, 10 \mathrm{mg} \text { and leuprolide arm } \\
\text { respectively }\end{array}$ & $\begin{array}{l}\text { Hypoestrogenic symptoms: } 11 \%, 10 \% \text { and } \\
40 \% \text { in women taking } 5 \mathrm{mg}, 10 \mathrm{mg} \text { and } \\
\text { leuprolide arm respectively }\end{array}$ \\
\hline $\begin{array}{l}\text { PEARL } \\
\text { III }\end{array}$ & $\begin{array}{l}13 \text { Weeks } \\
\text { (repeated } \\
\text { courses) }\end{array}$ & $\begin{array}{l}\text { Amenorrhea: } 79 \%, 89 \%, 88 \%, 90 \% \text { for courses } 1 \text {, } \\
2,3 \text { and } 4 \text { respectively of } 10 \mathrm{mg} \text { of UPA } \\
\text { Mean reduction in fibroid volume: } 45 \%, 63 \% \text {, } \\
67 \% \text { and } 72 \% \text { for the } 4 \text { courses of } 10 \mathrm{mg} \text { of } \\
\text { UPA }\end{array}$ & $\begin{array}{l}\text { All endometrial biopsies } \\
\text { Revealed benign changes with no atypia }\end{array}$ \\
\hline $\begin{array}{l}\text { PEARL } \\
\text { IV }\end{array}$ & $\begin{array}{l}12 \text { Weeks } \\
\text { (repeated } \\
\text { courses) }\end{array}$ & $\begin{array}{l}\text { Control of bleeding was }>80 \% \\
\text { Reduction in fibroid volume: } 54 \% \text { and } 58 \% \text { for } \\
\text { women taking } 5 \mathrm{mg} \text { and } 10 \mathrm{mg} \text { of UPA } \\
\text { respectively } \\
\text { Improved quality of life and pain control }\end{array}$ & $\begin{array}{l}\text { Less than } 5 \% \text { of patients discontinued due to } \\
\text { untoward effects }\end{array}$ \\
\hline
\end{tabular}

$10 \mathrm{mg}$ of UPA and $19 \%$ who received the placebo $(P<0.001$ when comparing each dose of UPA with placebo). Serious unpleasant events of uterine haemorrhage were noted in one patient who received $10 \mathrm{mg}$ of UPA and fibroid protrusion through the cervix in one patient who received placebo. Headache and breast tenderness were the most commonly encountered untoward effects associated with UPA and were not of great significance compared to placebo [18]. The trial clearly reflected the superiority of UPA in reducing excessive menstrual blood loss as well as successfully achieving significant diminution of fibroid size and uterine volume.

\section{PEARL II}

The PEARL II study was a follow-up from PEARL I as a double-blind trial comprising 307 women with symptomatic leiomyoma and excessive menstrual blood loss who were meant to be given oral UPA for 3 months daily $(5 \mathrm{mg}$ or $10 \mathrm{mg}$ ) or monthly injections of leuprolide acetate (of $3.75 \mathrm{mg}$ ) [21]. The result showed the control of uterine bleeding was achieved in 90\% of patients who received $5 \mathrm{mg}$ of UPA, $98 \%$ of those who were given $10 \mathrm{mg}$ of UPA and $89 \%$ of women who received leuprolide acetate- $\mathrm{a}$ difference (compared with leuprolide acetate) of 
$1.2 \%$ points (95\% confidence interval 9.3-11.8) for $5 \mathrm{mg}$ UPA and $8.8 \%$ points $(95 \%$ CI 0.4-18.3) for $10 \mathrm{mg}$ UPA. Moderate to severe hypoestrogenic symptoms such as hot flushes were observed in $11 \%$ of women who received $5 \mathrm{mg}$ UPA, $10 \%$ of those who received $10 \mathrm{mg}$ UPA and $40 \%$ of women who received leuprolide acetate $(P<0.001$ for each dose of UPA versus leuprolide acetate) [19].

\section{PEARL III}

PEARL III and PEARL III extension were trials with UPA courses and norethisterone acetate or placebo and the aim of further investigating the effectiveness and safety of UPA in the long-term management of symptomatic fibroids [22]. The trial was made up of 290 women who were symptomatic for uterine leiomyoma including heavy uterine bleeding who were given up to four 3-month $10 \mathrm{mg}$ daily courses of UPA, and this was followed straight away by 10-day double-blind treatment with norethisterone acetate (10 mg daily) or placebo. The result showed that after initiating the first course of UPA, the rate of amenorrhea was observed in $79 \%$ of patients with a median onset (from commencement of treatment) of 4 days (interquartile range 2-6 days). The median difference noted in the fibroid volume was $45 \%$. The rate of amenorrhea was $89 \%, 88 \%$ and $90 \%$ for the 131,119 and 107 patients who received treatment courses of two, three and four respectively. All endometrial biopsy histology samples were benign with no hyperplastic changes and there was no effect on fibroid volume or abnormal endometrial histology for women who were on norethisterone acetate [20].

\section{PEARL IV}

PEARL IV was a multicentre, randomised, double-blind, parallel-group, long-term trial evaluating the effectiveness and safety of UPA at a dose of $5 \mathrm{mg}$ or $10 \mathrm{mg}$ for the management symptoms of uterine fibroids. This trial was conducted in 46 study locations covering 11 countries between June 2012 and February 2014
[21]. A total of 451 women who were symptomatic for uterine leiomyoma including heavy uterine bleeding were recruited. They received two repeated 12-week courses of treatment of 5 or $10 \mathrm{mg}$ of UPA daily. Sixty-two percent and $73 \%$ of patients who received the two courses of treatment with $5 \mathrm{mg}$ and $10 \mathrm{mg}$ of UPA achieved amenorrhea [21]. Less than 5\% of patients discontinued treatment because of adverse effects but overall UPA was well tolerated [21]. This study built on the foundation of the previous PEARL studies further reflecting the benefits, effectiveness and safety of ulipristal in the control of symptoms of uterine leiomyoma (particularly bleeding and pain) with improved quality of life.

There are other studies besides PEARL studies that have evaluated UPA therapy for fibroids. A study by Biscione et al. in 2020 showed that ulipristal acetate is effective in improving different aspects of daily and sexual life (quality of life) of patients undergoing medical treatment for uterine fibroids [22]. Yet another study evaluated liver function in women treated with ulipristal acetate (UPA) and assessed the tolerability and satisfaction during treatment. This cross-sectional study included women with symptomatic uterine fibroids subjected to one or more 3-month treatment courses of $5 \mathrm{mg}$ UPA daily. Following European Medical Agency's prescriptions, women were asked about symptoms potentially related to liver damage and had blood tests done to assess serum levels of aspartate aminotransferase (AST) and alanine aminotransferase (ALT). Data on side effects, tolerability and satisfaction with the therapy were obtained during a phone interview. A total of 162 women completed the study with a mean treatment duration of $1.8 \pm 0.9$ cycles. No increased AST and ALT serum levels were detected, and no woman reported symptoms suggestive of liver injury. The majority of women reported improvement of fibroid-related symptoms and a high degree of satisfaction with treatment. More than half of women had side effects, in most cases not severe enough to discontinue therapy. Ulipristal acetate did not worsen liver function or cause severe organ injury and showed high tolerability and satisfaction profiles [22-27]. 


\section{WHAT WERE THE MAIN CLINICAL INDICATIONS FOR THE USE OF UPA AND WHAT DOSE WAS RECOMMENDED?}

NICE (National Institute for Health and Care Excellence) guidance on 'heavy menstrual bleeding (HMB)' advocated the use of UPA intermittently for medical management of fibroids in women not suitable for surgical intervention (where surgery may not be safe and beneficial or where the patient does not wish surgery) [15]. Daily $5 \mathrm{mg}$ dose of UPA can be given for up to four courses of treatment. This should be offered to women who present with $\mathrm{HMB}$ with a myoma size $\geq 3 \mathrm{~cm}$ diameter and for women with a haemoglobin level $\leq 102 \mathrm{~g} / \mathrm{l}$. The guidance also suggested considering UPA at $5 \mathrm{mg}$ daily dose for up to four courses for women with HMB with a myoma size $\geq 3 \mathrm{~cm}$ diameter and in women with a haemoglobin level $>102 \mathrm{~g} / \mathrm{l}$ [14]. It stressed the importance of documenting the discussion about relative merits and untoward effects of UPA with the patients, including the recognition symptoms and signs of liver damage, to help them make an informed decision. It was recommended that liver function should be assessed in women using UPA for the first two courses of treatment and further if clinically warranted [14].

There are several other studies that have evaluated the preoperative use of UPA. A prospective study compared enucleation time, total operative time and perioperative complications during laparoscopic myomectomy in patients pre-treated with UPA compared with untreated patients. Of the 74 patients who were enrolled, 29 were pre-treated with UPA and 45 did not receive any hormonal therapy before surgery. Surgeons, blinded to patient preoperative treatment, completed a three-item questionnaire after each procedure to evaluate surgical difficulty. Based on surgeon response, fibroids in the UPA group appeared softer and more difficult to enucleate because of less clear cleavage planes than in the control group. The overall difficulty of fibroid detachment from the myometrium was judged considerably higher in the UPA group. Despite this, enucleation time, total operative time and perioperative complications were not statistically different in the two groups. The authors concluded that fibroids in patients pre-treated with UPA are subjectively less easy to enucleate; however, surgical times and perioperative outcomes are not affected by pre-treatment with UPA [22-27]. Luketic et al. reported no difference in surgical experience for myomectomies of patients pre-treated with UPA versus those without medical pre-treatment [22-27]. Yet another study found that 3-month preoperative treatment with UPA increases the possibility of complete resection in high complexity hysteroscopic myomectomy. It decreases the operative time and improves patient satisfaction at 3 months from surgery [22-27].

From a practical clinical perspective, women nearer to menopause who are high risk for surgery or wishing to avoid surgical intervention may benefit from UPA treatment. Perimenopausal women often have irregular periods, and abnormal bleeding patterns in such women are exacerbated by the presence of fibroids. UPA therapy offered symptom suppression and the possibility of not needing more invasive alternative interventions. The other group of women who were most likely to benefit from UPA treatment were young women with symptomatic uterine fibroids who had no immediate plans to conceive. Even if these women were to undergo a myomectomy, they would be at risk of fibroid recurrence and a need for repeat myomectomy in future when they attempt for pregnancy. The UPA therapy could, therefore, be used in these women as a temporising strategy to avoid surgery. UPA therapy was going to be less likely to be successful in women with massive and/or multiple large fibroids, although this would have needed further evaluation in future studies [22-27].

\section{ADVERSE EFFECTS AND COMPLICATIONS}

The common adverse effects associated with UPA include gastrointestinal symptoms such as nausea and vomiting and less commonly dry mouth, appetite disorders, diarrhoea, flatulence, altered 
taste, dry throat and thirst. Other effects include headaches, back pain, pelvic pain, myalgia, breast tenderness, fatigue, menstrual cycle irregularity, altered mood and dizziness. The unusual or uncommon side effects include fever, chills, hot flashes, increased risk of infection, malaise, anxiety, drowsiness, impaired concentration, insomnia, vision disorders, loss of libido, skin reactions and vulval disorders. Rare complications of the medication include erythema of the eyes, abnormal eye sensation, syncope, tremor, vertigo, genital itching, painful intercourse and ovarian cyst rupture $[2,15]$. It is the reports on liver injury in the recent time that have led to the temporary suspension of the use of UPA, and we will discuss this in further details below.

UPA has distinct pharmacodynamic effects on the endometrium and these could result in endometrial changes on histology; these changes are said to be reversible in nature. Endometrial tissue evaluated by the National Institute of Health-sponsored workshop after exposure to UPA, mifepristone and asoprisnil showed small confirmation of mitosis, in accordance with the anti-proliferative effect of SPRMs. There was evidence of atypical hyperplastic changes. There was stromal asymmetry, conspicuous dilated cystic glands and growth in the epithelium with mixed oestrogenic and progestogenic epithelial activity [1]. Up till now, these histological changes have not been observed in clinical practice. These changes according to the panel were noted at be progesterone receptor modulator-associated endometrial changes (PAEC). With insufficient evidence of mitosis, the histopathologist may link the cystic glandular changes seen with SPRM with simple endometrial hyperplasia but must also recognise the drawback of misdiagnosing women with endometrial hyperplasia who are on SPRM. A reasonable body of evidence has noted thickened endometrium on ultrasound with the use of high- or low-dose mifepristone. It has also been opined that in contrast with endometrial changes seen with unopposed oestrogen, the changes observed in women on SPRM are linked to cystic dilatation of the endometrial glands and not due to endometrial hyperplasia. Evidence emanating from randomised controlled trials concerning the SPRM is encouraging. Annual pelvic ultrasonography should be offered to women on UPA. If endometrial thickening is seen on the ultrasound scan, then they must be told that this may be due to the effect of SPRM if given for $>3$ months. This is also associated with glandular changes and not hyperplasia and the histopathologist must be made aware of the progesterone receptor modulator-associated endometrial changes so as not to classify them as endometrial hyperplasia.

\section{CONTRAINDICATIONS AND CAUTIONS RELATED TO UPA TREATMENT}

The contraindications to using UPA are women with cancer of the cervix, ovary, uterus or breast, underlying hepatic disorders, unrecognised vaginal bleeding, vaginal bleeding not related to fibroids, pregnancy, breastfeeding and hypersensitivity to the medication $[1,15]$. Its efficacy is likely to be reduced when taken with combined oral contraceptives and progesterone-only contraceptives and therefore taking them together is not advised [1, 15]. UPA is metabolised by an enzyme system known as the cytochrome $\mathrm{P} 450$ family, and this may give rise to drug interaction with other medications metabolised by CP450. UPA is not advised for use in patients on medications that are cytochrome enzyme inducers/inhibitors as these can reduce its efficacy $[2,15]$.

\section{SAFETY PROFILE AND HEPATIC EFFECTS - SUMMARY OF CURRENT CLINICAL EVIDENCE}

The clinical safety of UPA has been reviewed and widely evaluated in the PEARL clinical trials. However, recent reports of possible liver toxicity have led to the temporary suspension of its use until an investigation into its hepatic effects is completed. The lack and paucity of evidence from randomised controlled trials must be regarded with some discretion as abnormal liver enzyme values are part of the 
Table 2 Summary of the liver profile safety data from PEARL studies

\begin{tabular}{|c|c|c|}
\hline Study & Efficacy data & Safety data \\
\hline $\begin{array}{l}\text { PEARL } \\
\text { I }\end{array}$ & $\begin{array}{l}\text { Three patients had ALT levels }>3 \\
\text { times the higher end of normal }\end{array}$ & These values returned to normal at the 6-month follow-up visit \\
\hline $\begin{array}{l}\text { PEARL } \\
\text { II }\end{array}$ & $\begin{array}{l}\text { No patient showed ALT levels more } \\
\text { than the higher end of normal }\end{array}$ & \\
\hline $\begin{array}{l}\text { PEARL } \\
\text { III }\end{array}$ & $\begin{array}{l}\text { No patient showed ALT levels more } \\
\text { than the higher end of normal }\end{array}$ & \\
\hline \multirow[t]{4}{*}{$\begin{array}{l}\text { PEARL } \\
\text { IV }\end{array}$} & \multirow[t]{4}{*}{$\begin{array}{l}\text { Four patients showed ALT levels more } \\
\text { than the higher end of normal }\end{array}$} & $\begin{array}{l}\text { For the first patient, ALT levels were high at screening, but at baseline } \\
\text { returned to normal and stayed normal during the study }\end{array}$ \\
\hline & & $\begin{array}{l}\text { The second patient was noticed to have cholelithiasis and had a } \\
\text { cholecystectomy and an emergency surgery due to small bowel } \\
\text { obstruction, following which the levels of the liver enzymes } \\
\text { remained normal during the study period }\end{array}$ \\
\hline & & $\begin{array}{l}\text { The third patient discontinued participation after the first course of } \\
\text { treatment }\end{array}$ \\
\hline & & $\begin{array}{l}\text { The fourth patient discontinued participation after the first month of } \\
\text { treatment }\end{array}$ \\
\hline
\end{tabular}

exclusion criteria in the research protocols. Indicators of drug-induced liver injury are raised serum liver enzymes alanine transaminase (ALT) and aspartate transaminase(AST) (levels $>$ three times the higher end of normal) and increase in the serum bilirubin level (twice the higher end of normal values) [28-30].

A phase I clinical trial of UPA reviewed 160 patients who were exposed to UPA at doses varying from $2.5 \mathrm{mg}, 5 \mathrm{mg}, 10 \mathrm{mg}, 20 \mathrm{mg}$ to $50 \mathrm{mg}$. Results from phase I trials did not reveal any change in liver enzymes as markers of liver damage [30].

Phase II clinical trials involved 152 cases given UPA at doses ranging from $2.5 \mathrm{mg}, 5 \mathrm{mg}$, $10 \mathrm{mg}$ to $20 \mathrm{mg}$. Results from this trial further revealed that the liver enzymes, particularly ALT and AST, were never above twice the upper limit of normal and total bilirubin was never $>$ 1.5 times the higher end of normal values [30].

Phase III trials evaluated 1556 women who took 5 and $10 \mathrm{mg}$ UPA for one or multiple 3 -month courses. ALT levels were analysed in seven patients and seen to be $>3$ times the higher end of the normal values. PEARL I revealed three patients who had liver enzyme levels (ALT) $>3$ times the higher end of normal. For PEARL II and III, no patients had ALT levels exceeding the higher end of normal [30]. For the PEARL IV study, four patients were noted to have ALT levels exceeding three times the higher end of the normal ranges [30]. The liver profile safety data from PEARL studies are summarised in Table 2.

It was concluded from the trials that although UPA is not a member of a family of medications known to cause drug-induced liver damage, some patients exposed to it may have developed idiosyncratic drug-induced liver damage with no markers to identify patients who may be susceptible before starting the medication. It was also noted from the trials that liver injury would never have been suspected from the trials as the medication was well tolerated by all participants [30].

The European Medicine Agency Pharmacovigilance Risk Assessment Committee (PRAC) reviewed the use of UPA because of cases and incidents of severe liver damage in women known to be on UPA for the management of 
moderate to severe symptoms of fibroids. In the UK, approximately 20,400 courses of treatment of UPA were distributed between October 1, 2016, and September 30, 2017, and in Europe, about 765,000 women were treated with UPA. Noted by the reviewers were: one case of hepatitis, which was a suspected drug reaction from the use of UPA, one case each of liver fibrosis and fatty liver-non-alcoholic, and eight cases of abnormal liver function assays linked with UPA [31-33]. Worldwide, there were reports of severe liver damage in five patients on UPA inclusive of four patients with liver failure requiring liver transplant [31].

In February 2018, the Medicines and Health Products Regulatory Agency (MHRA) in the UK released warnings regarding new temporary safety measures introduced for the use of UPA based on reports of severe liver injury. The measures included not starting new courses of treatment of UPA even in patients who have concluded earlier courses, ensuring that a test for liver function is carried out at least monthly in every woman on UPA, terminating treatment with UPA in any patient with liver enzyme levels that are $>2$ times the higher end of normal and closely monitoring and referring to the hepatologist for evaluation when appropriate. Also, repeating the liver function test in all patients 2-4 weeks after discontinuing the treatment is also advised. It was recommended that liver enzyme (ALT and AST) levels should be measured in all patients who have used UPA recently or who are currently on the medication and present with features indicative of liver injury (such as nausea, vomiting, malaise, right hypochondrial pain, anorexia, asthenia or jaundice). If liver enzyme ranges are $>2$ times the higher end of normal the treatment should be discontinued and the patient should be monitored closely with referral to the hepatologist as indicated clinically. Women on treatment with UPA should be adequately counselled about the features of liver damage [31]. These measures were to be observed awaiting the conclusion of the European review into the safety of UPA.

In August 2018, MHRA further released new guidelines regarding restricting the use of UPA for the management of symptomatic uterine fibroids. Cases of liver injury due to UPA were noted as rare and severe and included liver failure necessitating liver transplant [32]. A number of initiatives were suggested to reduce the incidence of such adverse effects of UPA [32].

\section{THE MEDICINE AND HEALTH PRODUCTS REGULATORY AGENCY (MHRA) RECOMMENDATIONS FROM THE EUROPEAN MEDICINE AGENCY PHARMACOVIGILANCE RISK ASSESSMENT COMMITTEE (PRAC)}

1. UPA could be used by women in the reproductive age group experiencing moderate or severe symptoms of fibroids not suitable for surgery. Each course of treatment should not be longer than 3 months and can only be restarted if there was a break period within courses of treatment. It could also be used as a preoperative adjunct treatment before surgery in women of reproductive age for one course [32].

2. Treatment with UPA should be instituted and overseen by a doctor with experience in managing uterine fibroids.

3. UPA is not for use in women with underlying liver disease [32].

MHRA outlined monitoring of liver function in women who are treated with UPA as follows:

Prior to commencing each course of treatment with UPA, a liver function test should be performed, and UPA should not be started in patients with baseline liver enzyme levels (ALT and AST) that are greater than twice the higher end of normal [32].

Liver function test should be done every month within the first 2 months of the treatment. For additional courses of treatment, liver function should be checked once prior to commencing every new treatment course and when it is indicated as necessary clinically. At the end of every course of treatment, a liver function test should be carried out after 2 to 4 weeks. Treatment with UPA should be stopped in 
women whose ALT or AST levels are $>3$ times the higher end of normal, and they should be monitored closely and a referral considered to the hepatologist if clinically indicated [32].

\section{TEMPORARY SUSPENSION OF THE USE OF UPA FOR FIBROIDS}

In 2018 EMA disclosed the rare but serious risk of severe liver damage with the use of UPA and measures were instituted to forestall this from occurring. Despite conformity to the measures, a new case of serious liver damage was noted [33]. Due to multiple incidences of liver damage including the ones that resulted in liver transplant in $>900,000$ women who have been managed with UPA for fibroids since its authorisation in 2012, EMA has commenced a fresh review. On March 12, 2020, the EMA safety body recommended the suspension of the use of UPA for the treatment of fibroids while a review of its overall safety was in progress. No patient is to be treated for the first time with the medication during the period of its suspension until conclusion of the review.

\section{ULIPRISTAL ACETATE FOR FIBROIDS-WHAT NEXT?}

Progesterone receptors play a key role in the regulation of reproductive function in the female genital system, mammary gland and brain but are also present in non-reproductive tissues such as the cardiovascular, musculoskeletal and central nervous system [15]. UPA is a SPRM, and it is biologically plausible that it may impact liver function through action on progesterone receptors in the liver and gall bladder. Due to recent reports of severe liver injury in women taking UPA, the European Medicines Agency has suspended the drug use until their review is completed into this matter. While it has been suggested that these cases of liver injury could be due to idiosyncratic reaction, further research is needed to evaluate the mechanisms by which UPA could impact liver function and develop biomarkers which could identify patients at risk of or susceptible to developing severe liver injury while taking UPA. Until the review concludes, and such information becomes available, UPA as a medical treatment option is unlikely to be available to women symptomatic for uterine fibroids.

\section{CONCLUSION}

UPA is one of the selective progesterone receptor modulators that was shown to be effective in the management of moderate to severe symptoms of uterine fibroids. Ulipristal acetate significantly reduces fibroid-related bleeding and leads to increased haemoglobin levels, good quality of life and better pain control. Generally, UPA was considered a well-tolerated drug, but there have been recent safety concerns regarding its impact on liver function. Until the latest investigation finishes and the panel conclusions are revealed, the use of UPA for treatment of symptomatic fibroids will remain suspended. This article is based on previously conducted studies and does not contain any studies with human participants or animals performed by any of the authors.

\section{ACKNOWLEDGEMENTS}

Funding. No funding or sponsorship was received for this study or publication of this article.

Authorship. All named authors meet the International Committee of Medical Journal Editors (ICMJE) criteria for authorship for this article, take responsibility for the integrity of the work as a whole, and have given their approval for this version to be published.

Disclosures. Emmanuel Ekanem and Vikram Talaulikar have nothing to disclose.

Compliance with Ethics Guidelines. This article is based on previously conducted studies and does not contain any studies with human participants or animals performed by any of the authors. 
Data Availability. Data sharing is not applicable to this article as no datasets were generated or analysed during the current study

Open Access. This article is licensed under a Creative Commons Attribution-NonCommercial 4.0 International License, which permits any non-commercial use, sharing, adaptation, distribution and reproduction in any medium or format, as long as you give appropriate credit to the original author(s) and the source, provide a link to the Creative Commons licence, and indicate if changes were made. The images or other third party material in this article are included in the article's Creative Commons licence, unless indicated otherwise in a credit line to the material. If material is not included in the article's Creative Commons licence and your intended use is not permitted by statutory regulation or exceeds the permitted use, you will need to obtain permission directly from the copyright holder. To view a copy of this licence, visit http://creativecommons.org/licenses/bync/4.0/.

\section{REFERENCES}

1. Talaulikar VS. Uterine fibroids and ulipristal. Obstet Gynaecol Reprod Med. 2014;24:254-5.

2. Donnez J, Courtoy GE, Donnez O, et al. Ulipristal acetate for the management of large uterine fibroids associated with heavy bleeding: a review. Reprod Biomed Online. 2018;37:216-23.

3. Khan AT, Shehmar M, Gupta JKU. Uterine fibroids: current perspectives. Int J Womens Health. 2014;6: 95-114.

4. Biglia N, Carinelli S, Maiorana A, et al. Ulipristal acetate: a novel pharmacological approach for the treatment of uterine fibroids. Drug Des Dev Ther. 2014;8:285-92.

5. Kalampokas T, Kamath M, Boutas I, et al. Ulipristal acetate for uterine fibroids: a systematic review and meta-analysis. Gynecol Endocrinol. 2016;32:91-6.

6. Khaund A, Lumsden MA. Impact of fibroids on reproductive function. Best Pract Res Clin Obstet Gynaecol. 2008;22:749-60.
7. Sinai V. Medical therapy for fibroids: an overview. Best Pract Res Clin Obstet Gynaecol. 2018;46: 48-56.

8. Donnez J, Donnez O, Dolmans MM. The current place of medical therapy in uterine fibroid management. Best Pract Res Clin Obstet Gynaecol. 2018;46:57-65.

9. Farris M, Bastianelli C, Rosato E, Brosens I, Benagiano G. Uterine fibroids: an update on current and emerging treatment options. Ther Clin Risk Manag. 2019;15:157-78.

10. Duhan N. Current and emerging treatments for uterine myoma-an update. Int J Womens Health. 2011;3:231-42.

11. Arendas K, Leyland NA. Use of ulipristal acetate for the management of fibroid-related acute abnormal uterine bleeding. J Obstet Gynaecol Canada. 2016;38:80-3.

12. Faustino F, Martinho M, Reis J, et al. Update on medical treatment of uterine fibroids. Eur J Obstet Gynecol Reprod Biol. 2017;216:61-8.

13. Talaulikar VS, Manyonda I. Progesterone and progesterone receptor modulators in the management of symptomatic uterine fibroids. Eur J Obstet Gynecol Reprod Biol. 2012a;165:135-40.

14. National Institute for Health Care and Excellence (2018) Heavy menstrual bleeding: assessment and management, https://www.nice.org.uk/guidance/ ng88/resources/heavy-menstrual-bleedingassessment-and-management-pdf-1837701412549. Accessed 1 Oct 2020.

15. Talaulikar VS, Manyonda I. Ulipristal acetate for use in moderate to severe symptoms of uterine fibroids. Women's Health. 2014;10:565-70.

16. Talaulikar VS, Manyonda IT. Ulipristal acetate: a novel option for the medical management of symptomatic uterine fibroids. Adv Ther. 2012b;29: 655-63.

17. Rabe T, Saenger N, Ebert AD, et al. Selective progesterone receptor modulators for the medical treatment of uterine fibroids with a focus on ulipristal acetate. Biomed Res Int. 2018;2018:1-12.

18. Donnez J, Tatarchuk TF, Bouchard P, et al. Ulipristal acetate versus placebo for fibroid treatment before surgery. N Engl J Med. 2012;366:409-20.

19. Donnez J, Tomaszewski J, Vázquez F, et al. Ulipristal acetate versus leuprolide acetate for uterine fibroids. N Engl J Med. 2012;366:421-32. 
20. Donnez J, Vázquez F, Tomaszewski J, et al. Longterm treatment of uterine fibroids with ulipristal acetate. Fertil Steril. 2014. https://doi.org/10.1016/ j.fertnstert.2014.02.008 (Epub ahead of print 2014).

21. Donnez J, Hudecek R, Donnez O, et al. Efficacy and safety of repeated use of ulipristal acetate in uterine fibroids. Fertil Steril. 2015;103:519-27.

22. Biscione A, Barra V, Bellone E, Severi FMLS. Ulipristal acetate on quality of life and sexual function of women with uterine fibromatosis. Gynecol Endocrinol. 2020;36:87-92.

23. Ferrero S, Racca A, Tafi E, Alessandri F, Venturini PLLRMU. Ulipristal acetate before high complexity hysteroscopic myomectomy: a retrospective comparative study. J Minim Invasive Gynecol. 2016;23: 390-5.

24. Del Forno S, Degli Esposti E, Salucci P, Leonardi D, Iodice R, Arena A, Raimondo D, Paradisi RSR. Liver function, tolerability and satisfaction during treatment with ulipristal acetate in women with fibroids: a single center experience. Gynecol Endocrinol. 2020;36:445-7.

25. Natalie Woodhead SI, Rachel Pounds PP. Ulipristal acetate for uterine fibroids: 2 years of real-world experience in a UK hospital. J Obstet Gynaecol (Lahore). 2018;38:813-7.

26. Frascà C, Arena A, Degli Esposti E, Raimondo D, Del Forno S, Moro E, Zanello M, Mabrouk MSR. First impressions can be deceiving: surgical outcomes of laparoscopic myomectomy in patients pretreated with ulipristal acetate. J Minim Invasive Gynecol. 2020;27:633-8.

27. Luketic L, Shirreff L, Kives S, et al. Does ulipristal acetate affect surgical experience at laparoscopic myomectomy? J Minim Invasive Gynecol. 2017;24: 797-802.

28. Chen M, Suzuki A, Thakkar S, et al. DILIrank: the largest reference drug list ranked by the risk for developing drug-induced liver injury in humans. Drug Discov Today. 2016;21:648-53.

29. Lammert C, Einarsson S, Saha C, et al. Relationship between daily dose of oral medications and idiosyncratic drug-induced liver injury: search for signals. Hepatology. 2008;47:2003-9.

30. Donnez J. Liver injury and ulipristal acetate: an overstated tragedy? Fertil Steril. 2018;110:593-5.

31. Branch S. Esmya (ulipristal acetate) for uterine fibroids: monitor liver function in current and recent users; do not initiate treatment in new users or those between treatment courses. Geneva: World Health Organization; 2015. https://doi.org/10. 22201/fq.18708404e.2004.3.66178.

32. Raine J. Esmya (ulipristal acetate) for symptoms of uterine fibroids: restrictions to use and requirement to check liver function before, during and after treatment. Geneva: World Health Organization; 2015. https://doi.org/10.22201/fq.18708404e.2004. 3.66178.

33. Agency EM. Esmya: new measures to minimise risk of rare but serious liver injury. 2018 